experienced a higher fall in marriage ages than others. The removal of marriages in which the bride was pregnant at marriage reduced the differentials somewhat; but left the principal conclusions unchanged.

Sir Aubrey Lewis dealt with demographic aspects of mental disorder and surveyed the statistics of different kinds of mental illness, stressing the increase in the rate for elderly persons. In the discussion, stress was laid on the considerable variation in the gecgraphical incidence of various forms of mental disorder, and Miss E. Brooke, from the General Register Office, surveyed some of the results of the Mental Health Survey undertaken by the Registrar General, and commented on the influence of social environment on the incidence of mental disease.

Prof. R. Freedman, of Michigan University, reported on norms for family size in underdeveloped countries. He reminded the audience that all societies regarded the number of children born to a couple as important both individually and socially, and that even in undeveloped societies potential measures of control were available. Surveys asking for the ideal number of children obtained answers which tended to cluster around modal values without great dispersion. Large numbers of children were not regarded as desirable in many undeveloped societies. He then turned to the problem of changing attitudes and said that one of the most important factors in spreading smaller norms was the enlargement of the social unit within which communication normally took place. The role of education and literacy, in his view, was much more important than had hitherto been recognized.

The symposium concluded with a closing statement by Prof. F. W. Notestein. He stressed the importance of demographic research, and deplored the inadequacy of funds available for its prosecution, both on the social and on the physiological side. More money was spent on the investigation of certain very rare and esoteric diseases than on the physiology of reproduction. While the reduction of fertility in countries which are at present growing rapidly was extremely important, he thought it vital that allocations of economic aid should not be made dependent on acceptance of birth control, as had been suggested in some quarters. The desire to limit family size would have to grow within these societies and any attempt to impose it by force or by certain economic sanctions could only lead to anti-Western political feeling being associated with opposition to reduced fertility. Economic development was a necessary condition before population growth eould be controlled. $\mathrm{He}$ felt that the symposium had served a useful purpose in bringing together scholars from different disciplines, and in showing how much each of them had to contribute to the study of human populations. The Royal Society was to be congratulated on arranging this meeting and he hoped that it would be followed by others, so that natural and social scientists would be able to collaborate in the broader study of mankind and its problems.

\title{
ADAPTIVE TEACHING MACHINES
}

\begin{abstract}
$\mathrm{A}^{\prime}$ $\mathrm{N}$ adaptive teaching machine is a machine that modifies its training programme to suit the student's individual requirements. Like the real-life teacher, it 'learns' about the student's difficulties and takes steps to remedy those misunderstandings which the student is unable to overcome by his own efforts. To achieve this objective, the adaptive teaching machine presents a sequence of instructional items on some suitably automated display, and a sequence of test items for establishing whether or not the instruction has been understood. Test items usually consist of questions to which the student must respond by pressing, within a given time allowance, an appropriate button or key. The working of the machine and the uses to which it may be put have been deseribed by B. N. Lewis of Birkbeck College, London*.

By noting on internal registers the speed and accuracy with which particular items are handled, the machine can build and maintain an up-to-themoment account of the student's strengths and weaknesses. Computations performed on these registers then enable the training programmes to be adjusted in ways that seem best suited to the student's special idiosyncrasies. In the simplest case, each register is concerned with detecting the presence of a distinct kind of misunderstanding or difficulty. Thus, if prior investigations have shown that a particular skill or subject-matter is susceptible to five basic misunderstandings (in the sense that five different 'dimensions of confusion' habitually operate to frustrate the learning process), the machine will need at least five

* The Science Teacher, 6, No. 1 (October 1962).
\end{abstract}

error registers on which to evaluate the student's mistakes.

If these registers are called $A, B, C, D$ and $E$, and the student's first mistake indicates (according to some pre-established criterion), the possibility of $A, B$ or $E$-type misunderstanding, and if the second mistake points to misunderstanding $B$ or $D$, then the two mistakes collectively suggest that misunderstanding $B$ is predominant. This information enables the machine to switch to a 'correctional programme' which explicitly concentrates on the removal of $B$, while at the same time continuing to secure evidence about the other possible misunderstandings.

Alternatively, the machine could continue to accumulate evidence over a much longer sequence of tests before taking corrective action. In either case the machine must contain an overall control mechanism that scans the states of its errors registers, performs the necessary computations, and adjusts its programme according to some built-in decision rule(s). These adjustments (and the decision rules on which they are based) conform to a well-designed plan and are in no way haphazard. Without exception, they are intended to keep the level of tuition within the rather narrow limits that the student himself determines. It is, therefore, essential that instruetion should be pitched at just the right level of difficulty and should be continuously adjusted as a function of the student's performance. The most direct way of adjusting difficulty is to vary the standard of the instructional items (by omitting some or modifying others), and to make correlative changes in the content of test items. But it is often 
more convenient to hold the instructional and test items fairly constant and to operate, on a separate display if nocessary, a variable supply of supplementary information and hints. In addition, it is useful to impose limitis on the time allowed for assimilating instructions and rosponding to test questions. The time limits can then be differentially adjusted so that longer time is allowed in respect of items that the subject is likely (according to the machine's computations) to find difficult.

These two gambits have been successfully used in several commercial teaching machinos of which the best known is the SAKI (Solatron Automatic Koyboard Instructor) device. This was pioneered by Gordon Pask for training operators on the 12-key 'Hollerith' card punch. Briefly, the system consists of a display unit that gives instructions and prompts, a keyboard which the trainee must operate (without looking at the koys), and an adaptive computer which 'senses' the characteristics of the student and adjusts the training programme to suit his needs. The display unit consists of a back-lighted exercise card (containing four lines of 24 figures) and an urray of 12 lights laid out in the same spatial pattern as the 12 keys on the keyboard. Since some combinations of figures are harder to punch than others, the exercise cards are changeable and are graded with respect to diffieulty.

The figuros on the exerciso card are illuminated one at a time (moving from left to right) and, for each figure that appears, a corresponding light shines in the 12-light array to indicate tho position of the key on the real keyboard. The trainee's task is to press the appropriate key within a given allowance. If he fails to do so, the figure is automatically replaced by the noxt figuro to the right, and the trainee is recorded as having made a mistake. During the early stages of learning the figures move on rather slowly. However, as the trainoo gains in spood and accuracy the waiting times become shorter, and the prompting lights (in the 12-light array) diminish in intensity. But this is done differentially, so that tho machine continues to wait Ionger and to give prompts on those keys which porsist in giving difficulty. Furthermoro, it will slow down and restore prompts in respect of any key on which the traineo has a sudden relapse. Whereas tho simpler teaching machines take corroctivo action on the basis of just ono rosponse, $\$ A K I$ adjusts its programme in accordance with an integrated performanco measure (based on speed and accuracy) assured over a whole series of rosponses. SAKI also 'paces' the student, by adjusting difficulty and time pressure so that he is always working near the limit of his ability.

This machino uses a technique that tends to minimize the amount of useful information gained about the student. For if the student were to be given easy problems that almost everyone could solve, little would be learned about him. Convorsoly, little is learned by loading him with problems which are beyond his capacity. An optimal 'in-between' stratogy is to start with easy problems and to step up their difficulty. But this moans the student is most likely to rovenl his incipiont weaknesses without, at the same time, wanting to withdraw from the situation. By keeping the student around tho threshold of his ability, his attention tends to be completely absorbod by the instructional material presented, and this renders him controllable for toaching purposes. As a further refinement the teachingmachine may conceal the fact that it has detected a weakness in tho student; in this way it can continue to probe for information without losing the student's goodwill.

The teaching principles embodied in SAKI are entirely genoral. Adaptive machines have been built to instruct such diverse skills as typing, faultfinding and equipment maintenance, radar training, pattern recognition, and inductive and deductivo reasoning. In every case the same dynamic rolationship is established between the student and machine, so that the student is spurred on to greater and greater efficiency under optimally congenial conditions. There are theoretical reasons for supposing that no teaching method could bo botter than this.

\section{THE COMMONWEALTH SCIENTIFIC AND INDUSTRIAL RESEARCH ORGANIZATION (AUSTRALIA)}

$T$ HE fourteenth annual report of the Common. wealth Scientific and Industrial Research Organization (Australia)*, covering the yoar onded June 30, 1962 , bosides the general review and brief survey of progress in research, includes lists of papers published during the year and details of membership of the Advisory Council, State Committees and staff, Of total expenditure of $£ 12,089,389, £ 1,122,354$ was on capital works, and of $£ 10,967,035$ spent on investigations, $£ 174,814$ went to the Commonwoalth Agricultural Buroaux and other outside bodies. Expenditure on the Animal Research Laboratories was $£ 1,190,120$; on plunt research, $£ 994,727$; ontomology, $£ 434,183$; soils research, $£ 360,048$; food preservation,

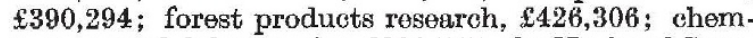
ical research laboratories, $£ 981,747$; tho National Standards Laboratory, $\$ 836,017$; fisheries and oceanography, £257,412; building research, $£ 208,046$;

* Commonwealth Seientinc and Industrial Regeareh Organization Australia. Fourteenth Annual Report, 1961-62. Pp. 1v + 153+10 plates. (Melbourne and Sydney: Commonwealth Scientific and Indus trial Research Organization, 1902). radiophysics, $£ 429,664$; wool research, $£ 711,331$; land research and regional survey, $£ 364,929$; dairy research, $£ 165,698$; tribophysics, £125,988; fuel research, $£ 299,203$; and wildlife survey, $£ 187,254$. During the year, 35 junior and 41 senior postgraduate studentships were a warded and 10 overseas studentships. The 210 -ft. radio-teleseope for the Division of Radiophysics was officially commissioned on October $31,1961$.

Among the legumes and grasses of value to the grass industry as a result of the work of the Tropical Pastures Division are Lotononis bainesii, Siratro and Numbank buffel grass, while 100 per cent prevention of Phalaris staggers was obtained by administration of heavy cobalt pellots along with steel grinders to cattle grazing on Phalaris tuberosa. A method of soil analysis has been developed to give a diroct assessment of the phosphate fertilizer requirements of wheat for the most economic return, and field experimonts indicate that the average rate of application of superphosphate in the southern wheat belt of New South Wales conld be increased to give returns of 